\title{
INFLUÊNCIA DAS MUDANÇAS CLIMÁTICAS NA PLUVIOMETRIA DA UNIDADE DE GERENCIAMENTO DE RECURSOS HÍDRICOS PIRACICABA/CAPIVARI/JUNDIAí
}

\author{
MOLON, Breno Fernando Pereira ${ }^{1}$; SILVA, Claudinei da ${ }^{1}$; RAMOS, Julio Cesar ${ }^{1}$; \\ APARECIDO, Rodolfo de Lima ${ }^{1}$; COSTA, Thiago Eduardo da Rocha ${ }^{1}$; MASSULO, Adélia ${ }^{2}$.
}

\section{RESUMO}

As variações climáticas estão em alterações constantes conforme o decorrer dos anos. Neste artigo, almeja-se avaliar a hipótese do crescimento da precipitação com o passar dos anos, perante a análise de dados históricos fornecidos pelas estações pluviométricas que integram o PCJ, no qual pode ser utilizado o método de Gumbel para a obtenção do valor máximo de precipitação para um determinado intervalo de 20 anos e período de retorno (Tr) também de 20 anos. Entende-se que as bacias hidrográficas e as conformações de drenagens que compõem as áreas de estudo, venham a sofrer um grande impacto devido à alta incidência dos raios solares nos oceanos provocados pelo efeito estufa, o que proporciona uma maior liberação de vapor d'água no circuito da corrente Amazônica, aumentando assim a precipitação nas estações pluviométricas da Bacia PCJ (Piracicaba, Capivari e Jundiaí). Nota-se um aumento significativo da precipitação em mais da metade das estações analisadas, fato que pode comprovar que há interferência das alterações climáticas nessa região.

Palavras-chave: Hidrologia. Precipitações. Variações Climáticas.

\begin{abstract}
Climate variations are constantly changing over the years. In this article, it is intended to evaluate the hypothesis of precipitation growth over the years, considering the historical data provided by the rainfall stations that integrate the PCJ, in which can be used the Gumbel method to obtain the maximum rainfall for a given interval of 20 years and return period ( $\mathrm{Tr}$ ) also for 20 years. It is understood that the watersheds and drainage conformations that make up the study areas will suffer a great impact due to the high incidence of solar rays in the oceans caused by the greenhouse effect, which provides a greater release of water vapour in the Amazonian current circuit, thus increasing precipitation in the PCJ Basin (Piracicaba, Capivari and Jundiaí) rainfall stations. There is a significant increase in precipitation in more than half of the analyzed stations, a fact that can prove the interference of climate change in this region.
\end{abstract}

Keywords: Hidrology. Precipitation. Climate Variation.

\footnotetext{
${ }^{1}$ Graduados em Engenharia Civil pelo Centro Universitário UNIFAAT, Atibaia, São Paulo.

${ }^{2}$ Mestre em Recursos Hídricos/UNICAMP, Doutoranda em Tecnologia/UNICAMP, Professora orientadora de trabalho de conclusão de curso da Engenharia Civil do Centro Universitário UNIFAAT.
} 


\section{Introdução}

Nos dias atuais, as mudanças climáticas ganham cada vez mais espaço nos estudos, o que justifica a pesquisa pelo enfático motivo do aumento e/ou diminuição da precipitação no decorrer dos anos, juntamente com seus diversos efeitos. Este estudo, por sua vez, busca um conhecimento com embasamento teórico em livros, autores e pesquisadores como os Meteorologistas, com o intuito de analisar as variações de precipitação que são de importância ímpar, já que através dos resultados obtidos, é possível traçar um plano a fim de amenizar os possíveis danos relacionados à sociedade contemporânea.

Nota-se que no Brasil, devido a sua diversidade climática, algumas anomalias aliadas ao fator precipitação são de grande relevância e podem estar atreladas a eventos climáticos como, por exemplo, as influências das chuvas perante interferência da corrente da Amazônia.

Deste modo, a partir da análise e obtenção de resultados de precipitações de estimativas máximas pelo método de Gumbel ao longo da bacia de pesquisa, são factíveis correções e planejamentos de controles de inundações e enchentes, tendo em vista que esses dados de precipitações pluviais podem estabelecer inferências sobre a dinâmica do regime pluviométrico do local e verificar o grau de significância em relação aos eventos atmosféricos estudados, buscando com isso uma melhor compreensão da disponibilidade hídrica para uma adequada estratégia econômica, social e ambiental.

\section{Metodologia Aplicada}

Para as estações úteis com mais de 20 anos de dados completos no ano foi aplicado o método de Gumbel. As estações incompletas que apresentam falhas na média anual não foram utilizadas.

É indicada a utilização do método de Gumbel com pelo menos vinte anos de dados completos. Logo, se aplicou o método a cada vinte anos intercalados voltando dez anos. A ideia principal é aplicar Gumbel várias vezes para cada estação e verificar a linha de tendência pluviométrica para cada estação.

Para a determinação da máxima precipitação algumas informações são necessárias, como a média das precipitações em um intervalo de 20 anos e o desvio padrão das precipitações. Segundo Righetto (1998), primeiramente deve-se isolar as máximas precipitações anuais em uma tabela e em seguida calcular a média e o desvio padrão. 
Para a análise de um determinado intervalo, primeiramente é calculada a média simples dos valores (soma dos valores divididos pela quantidade), seguidamente do cálculo do desvio padrão, conforme a Equação 1.

Eq. (1).

$$
D P=\sqrt{\sum_{i=1}^{n} \frac{(x i-M a)^{2}}{n}}
$$

Onde:

- $\sum$ - símbolo da somatória. Indica que temos que somar todos os termos, desde a primeira posição $(i=1)$ até a posição $n$;

- xi - valor na posição i no conjunto de dados;

- Ma - média aritmética dos dados;

- $\mathbf{n}$ - quantidade de dados.

Posteriormente é calculado o valor de $\boldsymbol{\alpha}$ e $\boldsymbol{\beta}$, conforme a Equação 2 e a Equação 3.

Eq. (2).

$$
\beta=\frac{6^{0,5} \cdot D P}{\pi}
$$

Eq. (3).

$$
\alpha=\mathrm{Ma}-(0,577 \text {. } \beta)
$$

Em seguida é aplicada a Equação de Righetto para distribuição de Gumbel com o objetivo da obtenção da máxima precipitação para o intervalo estudado. O resultado é obtido através da Equação 4.

Eq. (4).

$$
\left.\frac{\mathrm{P}(1 \text { dia; } \mathrm{T})-\alpha}{\beta}=-\ln \left[\ln \left(\frac{1}{(\mathrm{~F}(\mathrm{P}(\text { dia } ; \mathrm{T})}\right)\right)\right]
$$

Sendo: $\mathrm{T}=20$ anos o valor de $\mathrm{F}(\mathrm{P}(\operatorname{dia} ; \mathrm{T}))=1-(1 / 20)=0,95$.

Para os demais intervalos, foi repetido o mesmo procedimento e obtidos os valores, que foram apresentados em um gráfico e analisados pela sua linha de tendência, mostrando sua evolução ao decorrer dos anos. 


\section{Dados Característicos das Bacias}

A Divisão Hidrográfica Nacional, instituída pelo Conselho Nacional de Recursos Hídricos (CNRH), segundo a Resolução N³2, de 15 de outubro de 2003, estabelece doze Regiões Hidrográficas brasileiras que englobam: bacias, grupo de bacias ou sub-bacias hidrográficas de características naturais, sociais e econômicas similares. Esta divisão visa a orientar o planejamento e o gerenciamento dos recursos hídricos de todo o país, sendo as regiões estipuladas pela Agência Nacional de Águas (ANA): 1-Amazônica; 2-Tocantins/Araguaia; 3 Atlântico NE Ocidental; 4-Parnaíba; 5-Atlântico NE Oriental; 6-São Francisco; 7-Atlântico Leste; 8-Atlântico Sudeste; 9-Paraná; 10-Paraguai; 11-Uruguai e 12-Atlântico Sul, devidamente ilustrados pela Figura 1.

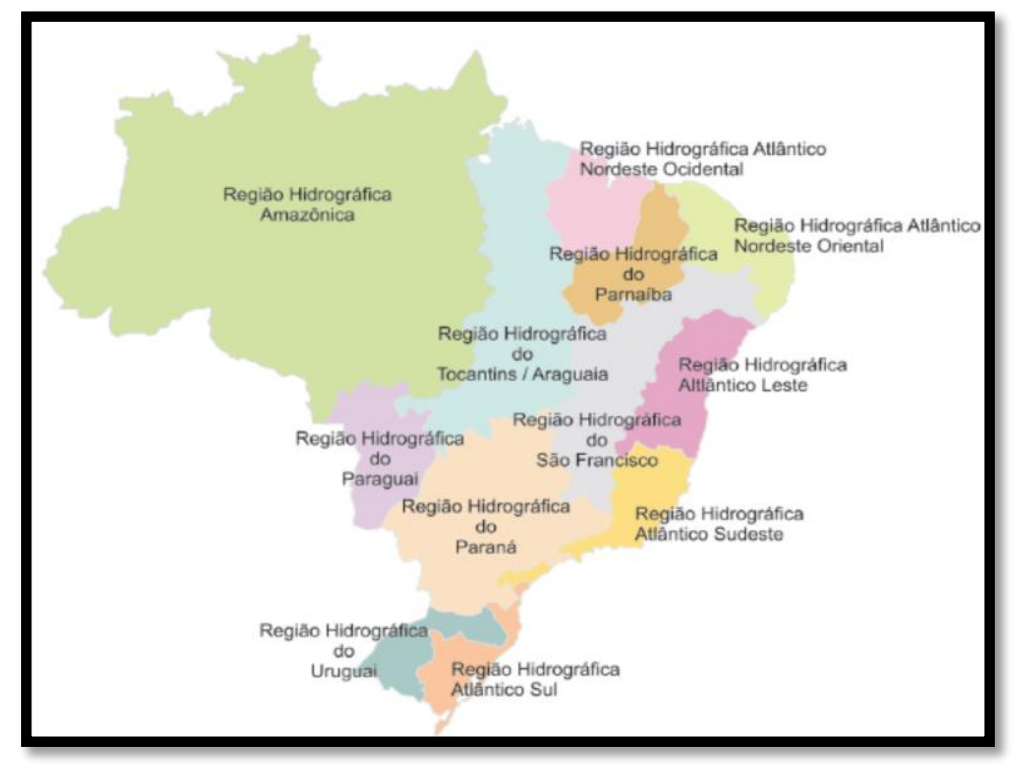

Figura 1 - Regiões Hidrográficas Brasileiras.

Fonte: CNRH (2003).

Segundo o MMA (2007), essas regiões têm sua divisão justificada pelas inúmeras diferenças existentes em todo o país, tanto no que se refere aos ecossistemas como também diferenças de caráter econômico, social e cultural, conforme já foram citadas, embora devidamente dispostas na Tabela 1. 
Tabela 1 - Diferenças entre as Regiões Hidrográficas Brasileiras.

\begin{tabular}{|l|c|c|c|}
\hline \multicolumn{1}{|c|}{ Região Hidrográfica } & $\begin{array}{c}\text { Vazão } \\
\text { média } \\
\left(\mathrm{m}^{3} / \mathrm{s}\right)\end{array}$ & $\begin{array}{c}\text { Densidade } \\
\text { demográfica } \\
1.000 \text { hab/km² }\end{array}$ & $\begin{array}{c}\text { Taxa de } \\
\text { Urbanização } \\
(\%)\end{array}$ \\
\hline Região Hidrográfica Amazônica & 131.947 & 2 & $67 \%$ \\
\hline Região Hidrográfica do Tocantins/Araguaia & 13.624 & 6 & $74 \%$ \\
\hline $\begin{array}{l}\text { Região Hidrográfica Atlântico Nordeste } \\
\text { Ocidental }\end{array}$ & 2.683 & 19 & $57 \%$ \\
\hline $\begin{array}{l}\text { Região Hidrográfica do Parnaíba } \\
\text { Região Hidrográfica Atlântico Nordeste } \\
\text { Oriental }\end{array}$ & 753 & 11 & $62 \%$ \\
\hline Região Hidrográfica do São Francisco & 2.850 & 20 & $76 \%$ \\
\hline Região Hidrográfica Atlântico Leste & 1.492 & 36 & $74 \%$ \\
\hline Região Hidrográfica Atlântico Sudeste & 3.179 & 118 & $90 \%$ \\
\hline Região Hidrográfica Atlântico Sul & 4.174 & 62 & $85 \%$ \\
\hline Região Hidrográfica do Uruguai & 4.121 & 22 & $68 \%$ \\
\hline Região Hidrográfica do Paraná & 11.452 & 62 & $91 \%$ \\
\hline Região Hidrográfica do Paraguai & 2.368 & 5 & $85 \%$ \\
\hline
\end{tabular}

Fonte: MMA (2007)

\section{Dados Característicos da Bacia PCJ}

As regiões das bacias dos Rios Piracicaba, Capivari e Jundiaí abrangem uma área de $15.320 \mathrm{~km}^{2}$, com 5.418.961 habitantes, a qual representa 7\% do Produto Interno Bruto (PIB) nacional (IBGE, 2004).

Entre os meses de outubro e abril, ocorre o período das chuvas, enquanto de maio a setembro ocorre o da estiagem. Em média, os índices de precipitação pluviométrica variam entre $1.200 \mathrm{~mm}$ e $1.600 \mathrm{~mm}$ anuais (CBH-PCJ, 2004).

Na região da Mantiqueira, próximo de Bragança Paulista, nos trechos de cabeceira dos cursos formadores do Rio Piracicaba, ocorrem as maiores precipitações pluviométricas, com índices que superam os $1.600 \mathrm{~mm}$. Já na região mais a leste, há um aumento da temperatura, com queda na precipitação, que em média alcança 1.300 mm. (IRRIGART, 2013). 


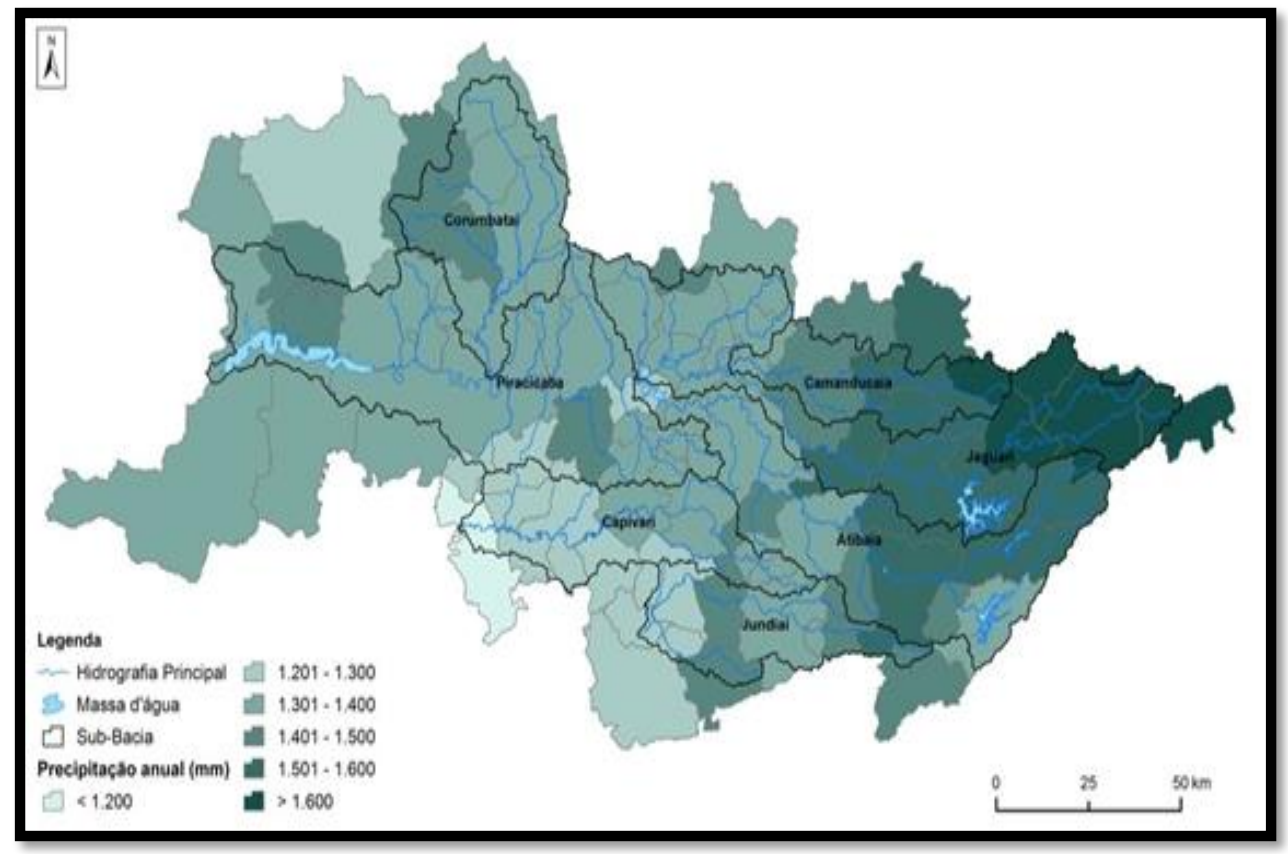

Figura 2 - Precipitação Anual (mm).

Fonte: IRRIGART (2013).

Sendo assim, de acordo com o Sistema Integrado de Gerenciamento de Recursos Hídricos do estado de São Paulo (SigRH), o Comitê de Bacias Hidrológicas dos Rios Piracicaba, Capivari e Jundiaí (CBH-PCJ) é o órgão que se faz responsável por gerenciar os recursos hídricos desta região desde o ano de 1993. Esta região é considerada crítica quanto à quantidade e qualidade das águas pluviais e possui algumas características peculiares:

- $\quad$ Área de drenagem: $15.320 \mathrm{~km}^{2}$.

- $\quad$ Extensão: aproximadamente $300 \mathrm{~km}$ no sentido Leste - Oeste e $100 \mathrm{~km}$ no sentido Norte - Sul.

- Principais rios: Atibaia, Atibainha, Cachoeira, Camanducaia, Capivari, Corumbataí, Jaguari, Jundiaí e Piracicaba.

- Municípios do estado de São Paulo e de Minas Gerais: Águas de São Pedro, Americana, Amparo, Analândia, Artur Nogueira, Atibaia, Bom Jesus dos Perdões, Bragança Paulista, Camanducaia, Campinas, Campo Limpo Paulista, Capivari, Charqueada, Cordeirópolis, Corumbataí, Cosmópolis, Elias Fausto, Extrema, Holambra, Hortolândia, Indaiatuba, Ipeúna, Itapeva, Itatiba, Itupeva, Jaguariúna, Jarinu, Joanópolis, Jundiaí, Limeira, Louveira, Mairiporã, Mombuca, Monte Alegre do Sul, Monte Mor, Morungaba, Nazaré Paulista, Nova Odessa, Paulínia, Pedra Bela, Pedreira, Pinhalzinho, Piracaia, Piracicaba, Rafard, Rio Claro, Rio das Pedras, Saltinho, Salto, Santa Bárbara D’Oeste, Santa Gertrudes, Santa Maria da Serra, Santo Antônio de 
Posse, São Pedro, Socorro, Sumaré, Toledo, Tuiuti, Valinhos, Vargem, Várzea Paulista e Vinhedo.

\section{Aplicação do Método de Gumbel}

No âmbito da hidrologia, os dados de precipitação são informações fundamentais para o entendimento do regime hidrológico de uma bacia de estudo. Logo todos os dados históricos consultados foram retirados do site da ANA, e para o desenvolvimento da análise, eles correspondem às estações pluviométricas que em arquivos de padrão Excel (xls) fornecem as precipitações máximas mensais. Já para a realização da análise da precipitação em diferentes intervalos (anos) será aplicado o conceito de distribuição de Gumbel, que é muito utilizado no Brasil e Canadá quando se desejam obter as máximas de precipitações e enchentes e de algumas outras análises de vazões (RIGHETTO, 1998).

Para todas as estações foram utilizados os dados diários de precipitação, verificando minuciosamente a ocorrência de falhas.

\section{Corrente da Amazônia}

A corrente da Amazônia é dependente de dois fatores importantes para a sua concepção. Sendo que o primeiro é o volume de umidade advinda do Oceano Atlântico (Figura 3) nas proximidades da Linha do Equador, onde as águas deste oceano recebem os raios solares perpendiculares devido à relação da posição da Terra com o sol. (SALATI,1983).

A vaporização das águas oceânicas é transportada por meio da ação dos ventos para o interior do continente em direção à região nordeste do país, que apresenta característica de relevo de baixa altitude e topografia plana, a qual facilita a entrada desta vaporização na mata amazônica. Estima-se um valor aproximado de 202 mil toneladas de vapor d'água por segundo em uma área de 6 milhões de quilômetros quadrados (CORREIA, 2008). 


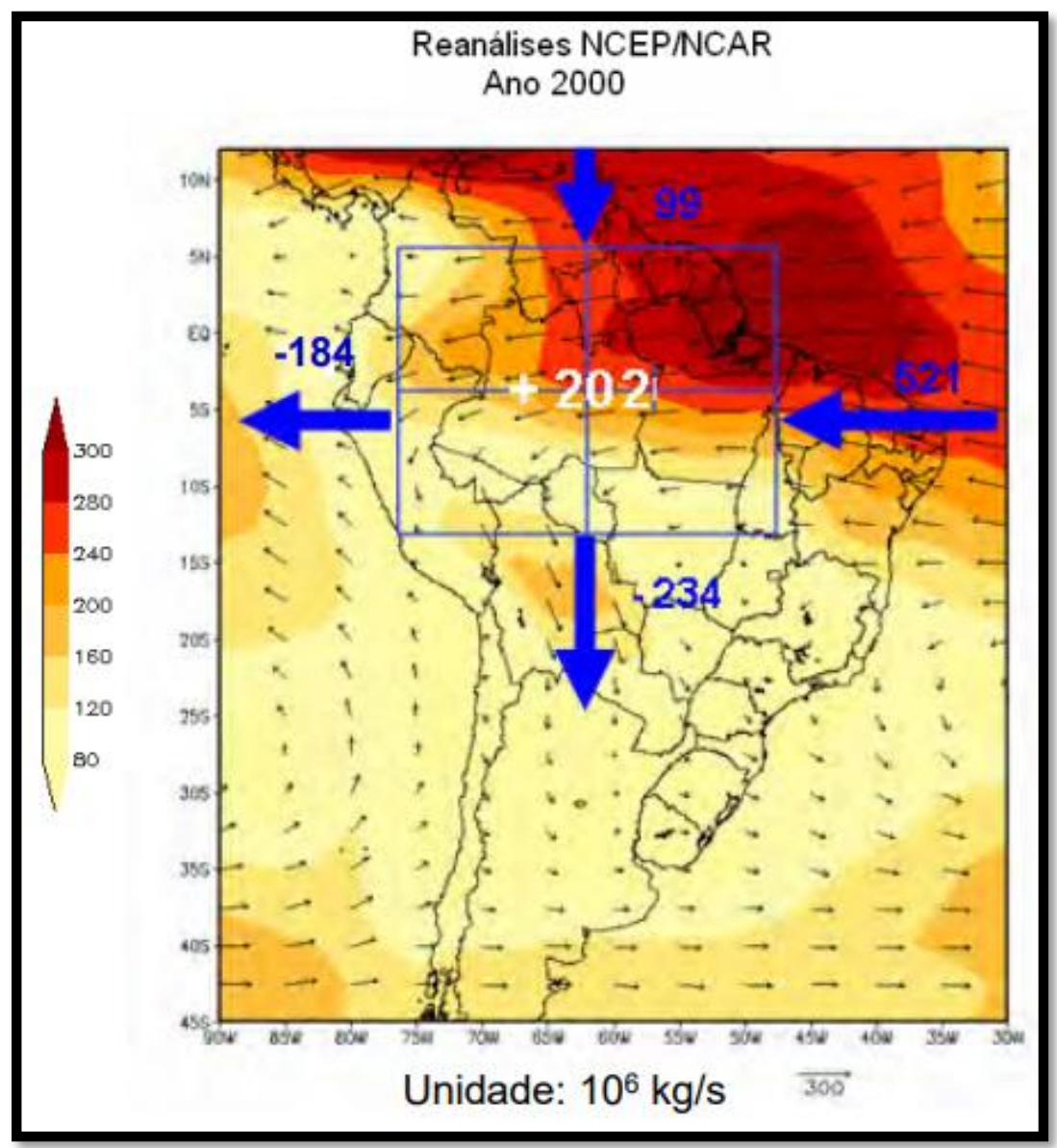

Figura 3 - Vaporização das Águas Advindas do Oceano Atlântico.

Fonte: CORREIA (2008).

Levantamentos apontam que o volume de umidade exportado em forma de vapor é de cerca de 3,4 bilhões de metros cúbicos, dado este importante para o equilíbrio das regiões que compõem a bacia amazônica. A conservação da floresta é um dos fatores que auxiliam na manutenção e equilíbrio dos recursos hídricos, evitando assim a possibilidade de um desabastecimento dos reservatórios, causando problemas à sociedade, agronegócio, logística, agropecuária, entre outros. (FEARNSIDE PHILIP, 1980).

\section{Clima no Brasil e no Mundo}

Nas últimas décadas o assunto sobre a mudança climática tem despertado o interesse de chefes de Estado, Governos, ONGs, empresas, entre outros. Esse processo de mudança climática é decorrente de efeitos acumulativos causados principalmente pela ação humana, que por sua vez, de forma contínua após a revolução industrial e tecnológica dos últimos séculos, 
emite de forma desordenada gases de efeitos estufa, aerossóis, entre outros degradantes (CAMILLONI \& BIDEGAIN, 2005).

O Brasil tem grande importância quando abordamos o assunto clima/poluição, pois possui uma floresta que funciona como armazenadora de Dióxido de Carbono $\left(\mathrm{CO}_{2}\right)$. Outro fator, porém de forma negativa, é a posição que o Brasil se encontra no ranking dos maiores poluidores do mundo, ocupando a $7^{\mathrm{a}}$ posição, segundo o Climate Data Explorer do World Resources Institute (2017). Esses fatores citados são causados em sua maioria pela emissão de poluentes na atmosfera devido às queimadas de florestas e pelo uso de combustível fóssil nas indústrias e pelos transportes (MENDONÇA, 2003).

Quando o tema é relacionado ao futuro do clima, o assunto é logo associado com os problemas causados pelos efeitos prejudiciais ao mesmo, os quais podem levar a tragédias, regime de chuvas, enchentes, secas prolongadas, tornados, transbordamento de rios, erosões, causando perturbações, infestações e doenças ao ser humano (PAPINI, 2009).

Com o aumento na concentração dos gases do efeito estufa, aliado às atividades antrópicas, proporciona-se um aumento significativo da temperatura da superfície do planeta Terra de aproximadamente $0,2^{\circ} \mathrm{C}$ nas últimas décadas, e $0,8^{\circ} \mathrm{C}$ no século passado (MARENGO et al., 2001). Esse aumento de temperatura se concentrou mais nos continentes e no hemisfério Norte (HANSEN et al, 2006).

A temperatura em elevação também proporciona o derretimento das camadas polares e consequentemente a elevação dos oceanos, causando grandes problemas para a economia dos países com acesso ao mar. Outro fator que causa esse aumento de temperatura são as perturbações das correntes marítimas e com isso todo o ciclo hidrológico, biomas, agricultura, fertilização e outros são severamente modificados (MARENGO, 2001).

Com o problema iminente a Organização Meteorológica Mundial (OMM) e o Programa das Nações Unidas para o Meio Ambiente (PNUMA) desenvolveram o Painel Intergovernamental sobre Mudanças Climáticas (IPCC) no ano de 1988, com o objetivo de pesquisar e analisar de forma sistemática com metodologias científicas aceitas no mundo acadêmico as mudanças climáticas e seus possíveis impactos que possam vir a ser causados a curto e longo prazo (LINO, 2009).

Os governantes, percebendo que a economia afetada já estava apresentando os efeitos negativos no agronegócio, agropecuária, turismo, logística e outros, deram ênfase à assinatura de diversos tratados como Rio-92, Protocolo de Kyoto 1997, Rio + 10, entre outros não menos importantes (GRAMKOW, 2011). 
As políticas protecionistas, infelizmente, não estão sendo suficientes para combater esses problemas, e os países em desenvolvimento como o Brasil, de modo geral, são uns dos mais afetados, devido à falta de infraestrutura e à presença de políticas públicas ineficientes, corrupção em níveis profundos, que acabam agravando a vida da sociedade como um todo. (NOBRE et al., 2005).

\section{Resultados e Análise de Dados Coletados}

Através das 192 estações obtidas e analisadas operantes das bacias estudadas (PCJ), apenas o quantitativo de 118 contribuíram significativamente para a análise, as quais foram classificadas em três tipos:

- $\quad$ Crescentes (linha de tendência com precipitação em crescimento);

- $\quad$ Decrescentes (linha de tendência com precipitação em decréscimo);

- $\quad$ Únicas (dados que contemplam apenas um intervalo).

Para o tipo denominado crescente, foram conferidas 55 estações contribuintes, com características semelhantes ao Gráfico 1, onde é possível notar um crescimento na linha de tendência do primeiro intervalo para o último analisado.

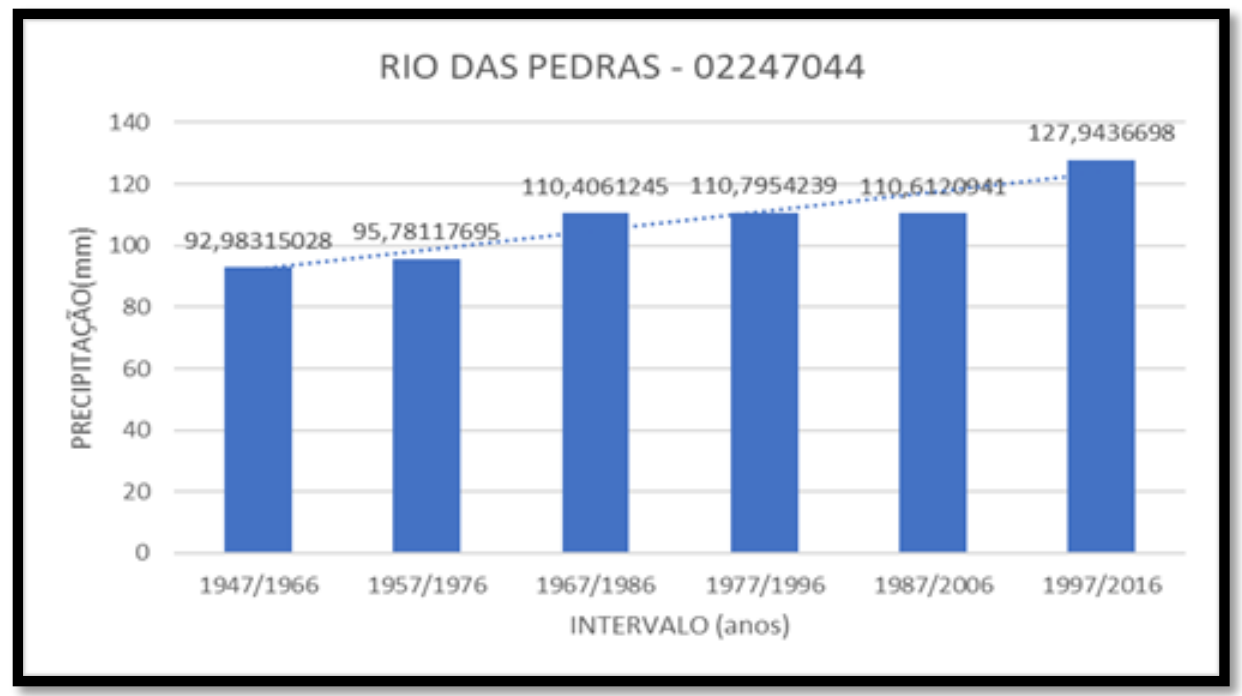

Gráfico 1 - Crescimento da Precipitação

Fonte: Os autores

Para o tipo denominado decrescente, foram computadas 29 estações, com características semelhantes ao Gráfico 2, onde é possível notar um decréscimo na linha de tendência do primeiro intervalo para o último analisado. 


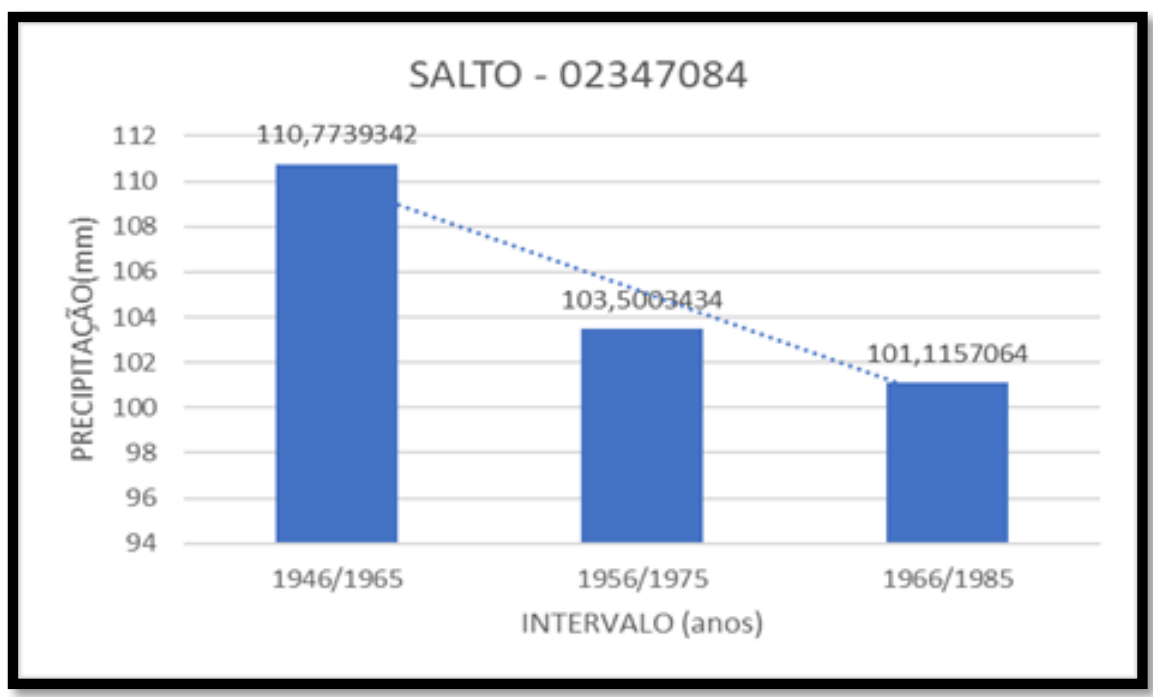

Gráfico 2 - Decréscimo da Precipitação

Fonte: Os autores

Para a denominada como única, foram computadas 34 estações, com características semelhantes ao Gráfico 3, apresentando estações com apenas um único intervalo de 20 anos e sendo descartadas, pois não há como realizar comparações em questão da sua evolução.

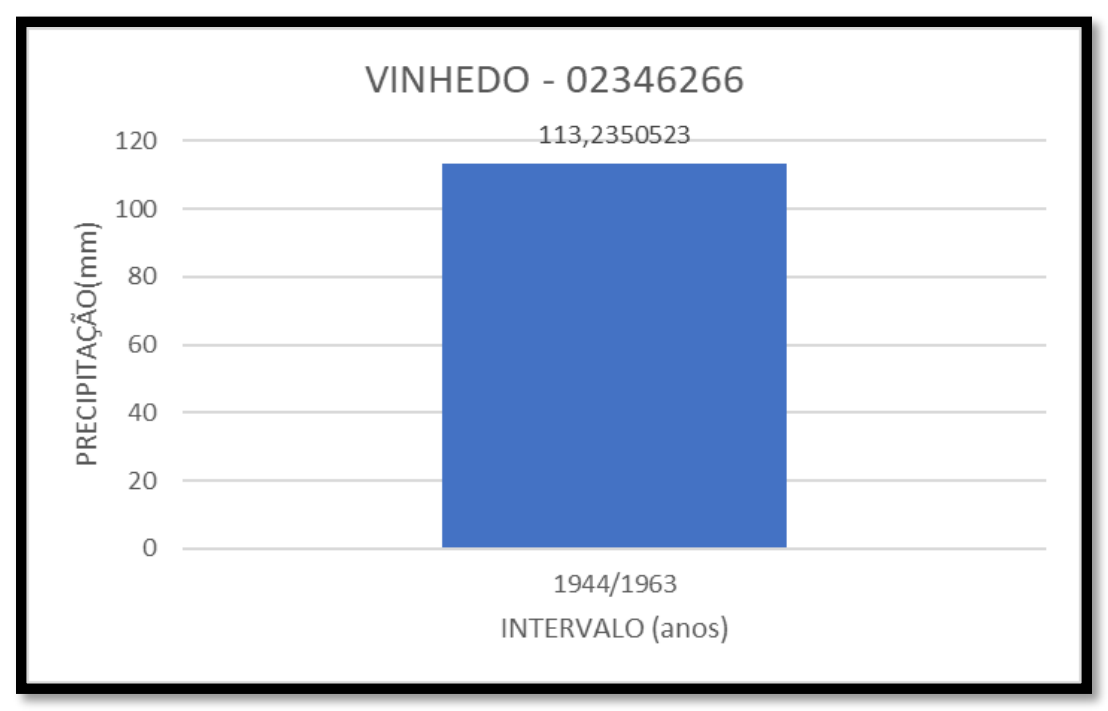

Gráfico 3 - Estação do Tipo Única

Fonte: Os autores

Contudo, se for realizada uma análise mais profunda que abrange os dados coletados e analisados, é possível observar se a quantidade de precipitação de chuva (mm) aumentou ou diminuiu num determinado período, para a referida pesquisa o período adotado destinou-se a 20 anos contínuos. No entanto, é descartada a porcentagem conhecida como "Única", 
exemplificada pelo Gráfico 3, possibilitando a disposição de "Crescente" e "Decrescente" pelo Gráfico 4.

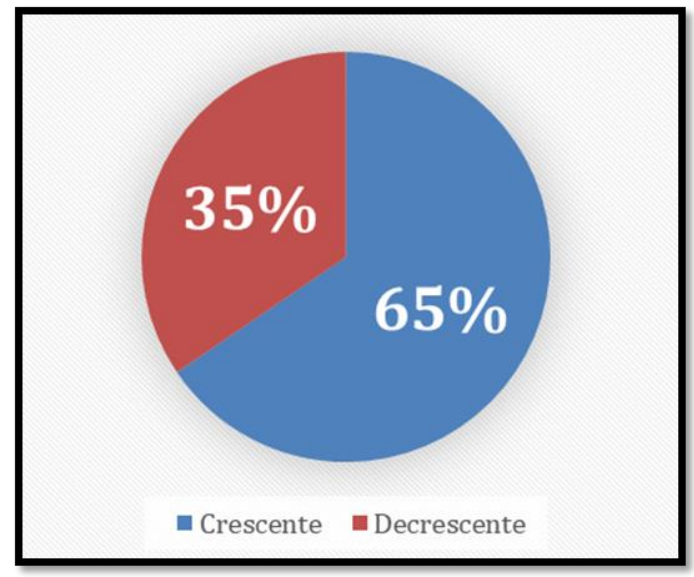

\section{Gráfico 4 - Percentual de Estações "Crescentes" e "Decrescentes" \\ Fonte: Os autores}

As porcentagens apresentadas pelo gráfico acima demostram que houve um crescimento da precipitação em $65 \%$ das estações analisadas, sendo que em $35 \%$ das estações decresceu. Fato este relevante para o planejamento urbano, abastecimento humano, defesa civil, antecipação de possíveis catástrofes, hidrelétricas e PCHs (Pequenas Centrais Hidrelétricas).

Com base no conhecimento adquirido através do estudo e dos dados obtidos e informações coletadas no decorrer do desenvolvimento da pesquisa, foram levantadas 192 estações pluviométricas da ANA (Agência Nacional de Águas), pertencentes à região que delimita a Bacia de Piracicaba, Capivari e Jundiaí (PCJ), sendo que 118 delas se apresentaram aptas para a obtenção destas precipitações máximas pelo método de Gumbel, o qual teve os cálculos aplicados para cada estação.

De acordo com os resultados apresentados, 55 estações tiveram a precipitação crescente, em 24 unidades a precipitação foi decrescente e em 29 estações não se contabilizou no cálculo, pois nestas havia ausência de dados, assim sendo, não poderão ser contabilizadas na análise pelo método de Gumbel.

Os dados coletados indicam que a precipitação em $65 \%$ das estações sofreu acréscimo, fator que é de grande importância para o desenvolvimento econômico e social da região, pois esses fatores interferem de forma direta no planejamento de abastecimento de água, defesa civil (antecipação de possíveis catástrofes), hidrelétricas e PCHs. Sendo que a corrente da Amazônia, os efeitos do aquecimento global, as queimadas, a industrialização são características possíveis a estas mudanças, entre outras apresentadas. 
Um dos fatores que podem ser considerados importantes para essa análise é a interpretação realizada por Crockford e Richardson (2000), que traz em sua linha de raciocínio a diferenciação de climas que se dá por diversos fatores, entre eles a sua localização geográfica, a incidência solar, o período, a inclinação da Terra, a geografia montanhosa ou planície, a vegetação, as correntes marítimas, o fluxo dos ventos etc. Caraterísticas estas que vão ao encontro da pesquisa em questão, pois na Linha do Equador, próximo à região Nordeste da costa brasileira, no Oceano Atlântico, há uma incidência muito grande dos raios solares que causam uma exposição contínua e crescente com o passar dos anos (SALATI, 1983).

Devido à exposição contínua e intensa do oceano aos raios solares proporciona-se a vaporização das águas oceânicas, que com ação das correntes marítimas levam-nas em forma de vapor d'água (nuvens) até o continente pela região Nordeste do Brasil. Grande parte desta precipitação não ocorre na região Nordeste, pois essa região possui correntes de ventos que conduzem o condensado até a região da Amazônia, até mesmo porque a topografia da região Nordeste brasileira possui caraterísticas topográficas planas, facilitando assim a entrada deste condensado na mesma.

A região Amazônica brasileira e dos países vizinhos possui uma vegetação com árvores de copas grandes, facilitando assim o processo de evapotranspiração que libera grande quantidade de vapor d'água, o qual se mistura com as nuvens que vêm do Oceano Atlântico, detalhadas anteriormente, também denominadas de "água verde".

Um dado relevante apresentado pelo pesquisador Salati (1983) e António Ocimar Manzi, do Instituto Nacional de Pesquisas Espaciais (INPE), indica que 1 metro quadrado $\left(\mathrm{m}^{2}\right)$ de vegetação leva à atmosfera cerca de seis a sete vezes mais água do que 1 metro quadrado $\left(\mathrm{m}^{2}\right)$ de oceano, sendo que boa parte disso se destina para a região Centro-Oeste e Sudeste do Brasil, esse fenômeno é conhecido por alguns autores como "Rios Voadores", devido à quantidade de água armazenada e transportada.

A soma das umidades advindas do Oceano Atlântico e da Floresta Amazônica segue em direção à Cordilheira dos Andes, por força dos ventos desta região, que sopram da porção leste para a porção oeste, porém, devido à presença de montanhas altas, apenas uma pequena porção ultrapassa os cumes, assim sofrendo interferências das correntes que se encaminham para o Sudeste e Sul do Brasil, como demonstra a Figura 4, logo esta umidade será direcionada à área de estudo do referido projeto perante os meses de novembro a abril. 


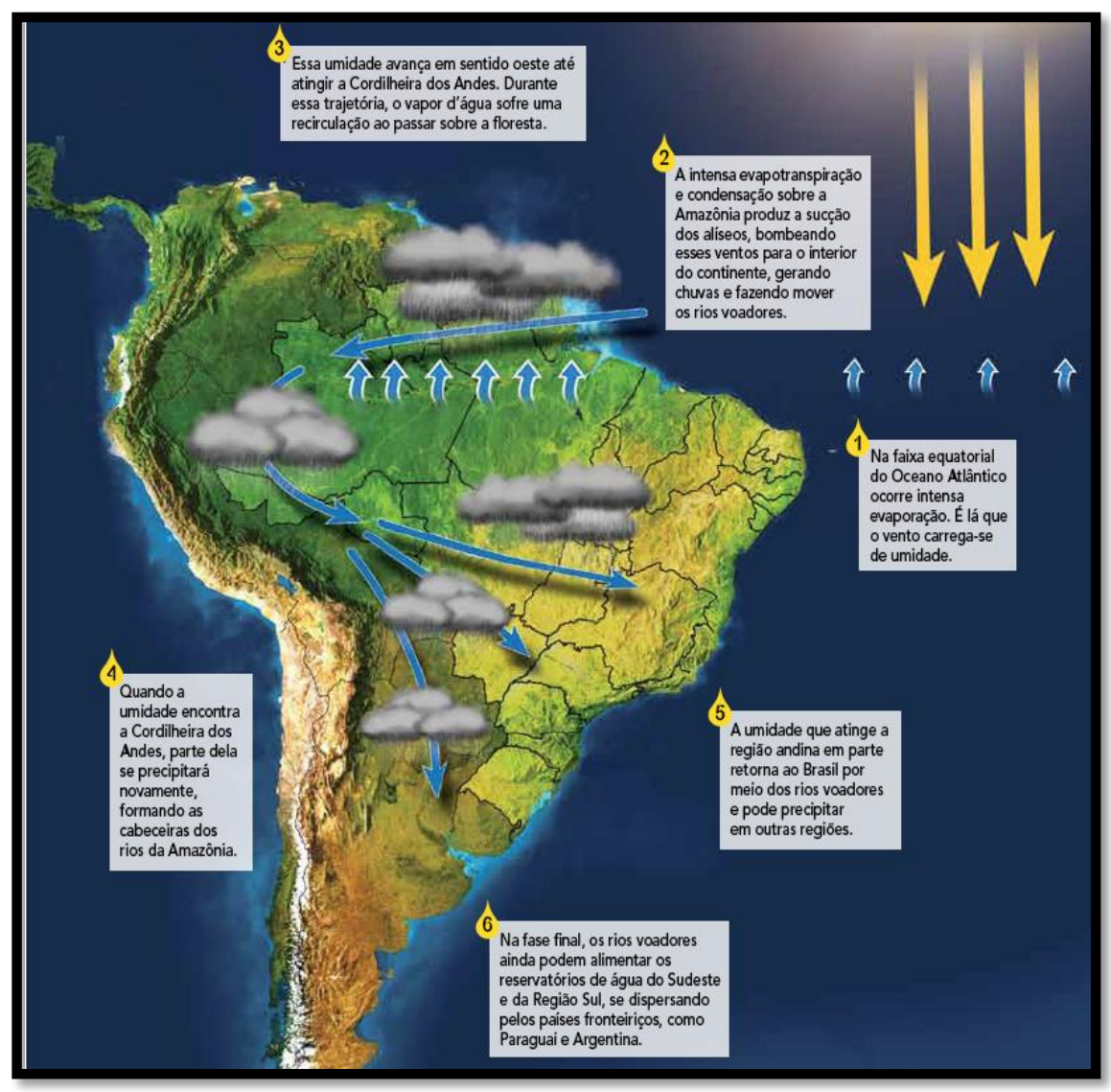

Figura 4 - Trajeto dos Rios Voadores.

Fonte: SALATI (1983).

As chuvas são mais concentradas na região entre os estados de São Paulo, Minas Gerais e Rio de Janeiro, pois a geografia do local conta com duas cadeias de montanhas elevadas, as quais são chamadas de Serra da Mantiqueira e Serra do Mar, essas por sua vez fazem com que grande parte desta porcentagem em forma de chuva precipite nas regiões dos estados de São Paulo, Minas Gerais, Espírito Santo e Paraná e uma porcentagem pequena de umidade se esvazie para o Oceano Atlântico.

Como perceptível acima o ciclo hidrológico da Corrente da Amazônia se inicia no Oceano Atlântico, mais precisamente na faixa da Linha do Equador, enfatizando a incidência solar nessa faixa, pois o fenômeno do aquecimento global tem se intensificado nas últimas décadas devido à liberação excessiva de $\mathrm{CO}_{2}$ pela industrialização e queimadas, enxofre e outros componentes preponderantes a esse fenômeno, com a evidência do aumento da temperatura no planeta Terra, incluindo o ambiente e as águas oceânicas, fenômeno que proporciona uma maior evapotranspiração.

Todos os fatores descritos devem ser levados em conta como possíveis causas e características para o aumento da precipitação, tendo em vista que, em 65\% das estações 
pluviométricas, houve elevação no nível das chuvas, como por exemplo, a unidade da cidade de Mairiporã/SP demonstrada pelo Gráfico 5 e da cidade de Atibaia/SP, pelo Gráfico 6.

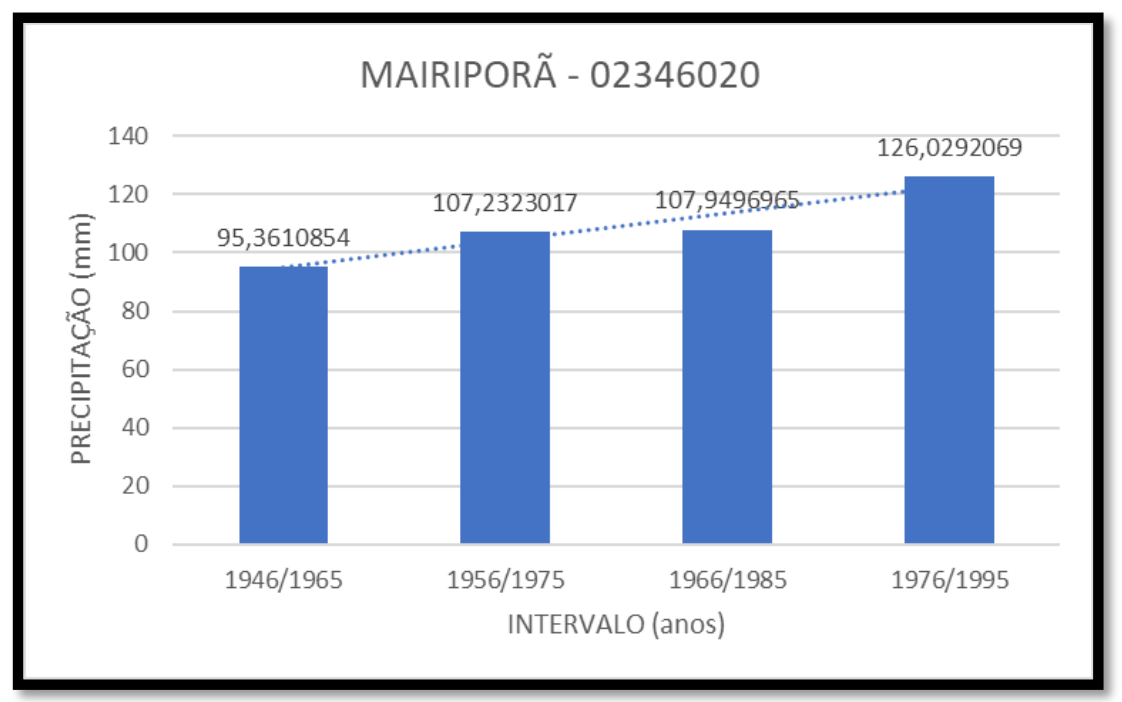

Gráfico 5 - Resultados da Estação 02346020 - Mairiporã/SP

Fonte: Os autores

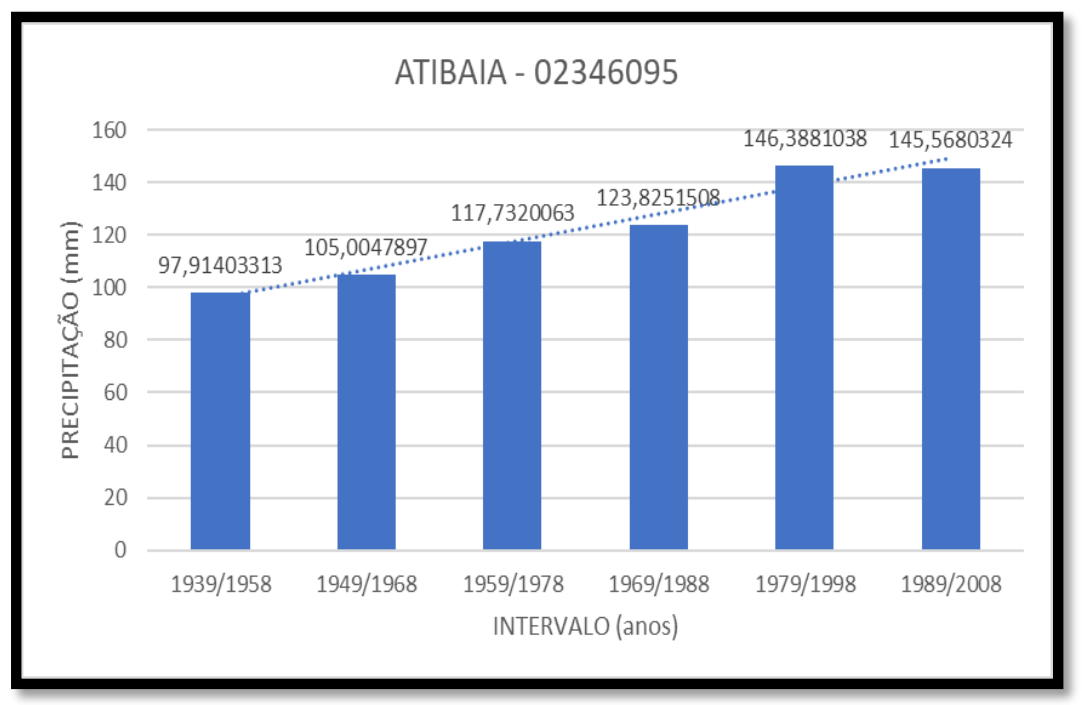

Gráfico 6 - Resultados da Estação 02246095 - Atibaia/SP

Fonte: Os autores

No caso de Atibaia/SP o Gráfico 6 demonstra primeiramente nas décadas de 1939 a 1958 a média de 97,91mm de precipitação, e no período de 1989 a 2008 a média de 145,57mm, representando aproximadamente um diferencial positivo crescente de 47,66 mm e uma linha de tendência crescente. Dados consideravelmente elevados quando pensamos em pluviometria no âmbito da Hidrologia. A mesma análise pode ser aplicada ao Gráfico 5, referente à cidade de 
Mairiporã/SP, onde o diferencial entre a primeira década analisada e a última foi de $30,67 \mathrm{~mm}$ com linha de tendência também crescente.

Calcula-se, de acordo com Fearnside (1980), que 3,4 trilhões de $\mathrm{m}^{3}$ são desembocados no circuito onde a corrente da Amazônia percorre. Para exemplificar esse volume de água daria para preencher cerca de 14 bilhões de piscinas olímpicas cujo volume é de $2.500 \mathrm{~m}^{3}$, outra comparação pode ser aplicada com relação ao consumo de água mensal por habitante no município de São Paulo/SP, que é de 3,3 m²/pessoa/mês, onde teríamos o abastecimento mensal garantido para 1,13 trilhões de pessoas.

Segundo estudos sobre o ciclo hidrológico do meteorologista Heinz Lettau, do Instituto Nacional de Pesquisas Espaciais (INPE), e a literatura referenciada por Correia (2008), as chuvas no estado de São Paulo e na bacia de estudo provêm: da porção oeste de outra bacia (Rondônia e Acre), do oeste do Amazonas e da Bolívia. Isso demostra o quanto é importante a preservação da Floresta Amazônica, políticas e leis de proteção à região, fiscalização de garimpo em áreas de florestas para o cultivo da agricultura em larga escala como a soja e a pecuária intensiva, que de forma direta ou indireta podem proporcionar um diferencial no aumento do volume de chuvas.

Quando se fala em preservação da natureza, efeitos causados pelo aquecimento global e a liberação de toneladas diárias de componentes na atmosfera que prejudicam o equilíbrio da natureza, não é possível deixar de relatar a questão das queimadas. Na Figura 5, desenvolvida por satélites e apresentada pelo DETER/INPE, observamos áreas desmatadas e focos de incêndio, que têm os estados de Rondônia e Acre como principais alvos, fato que somado com outras caraterísticas pode ser preponderante nas próximas décadas de uma nova crise hídrica ao estado de São Paulo. 


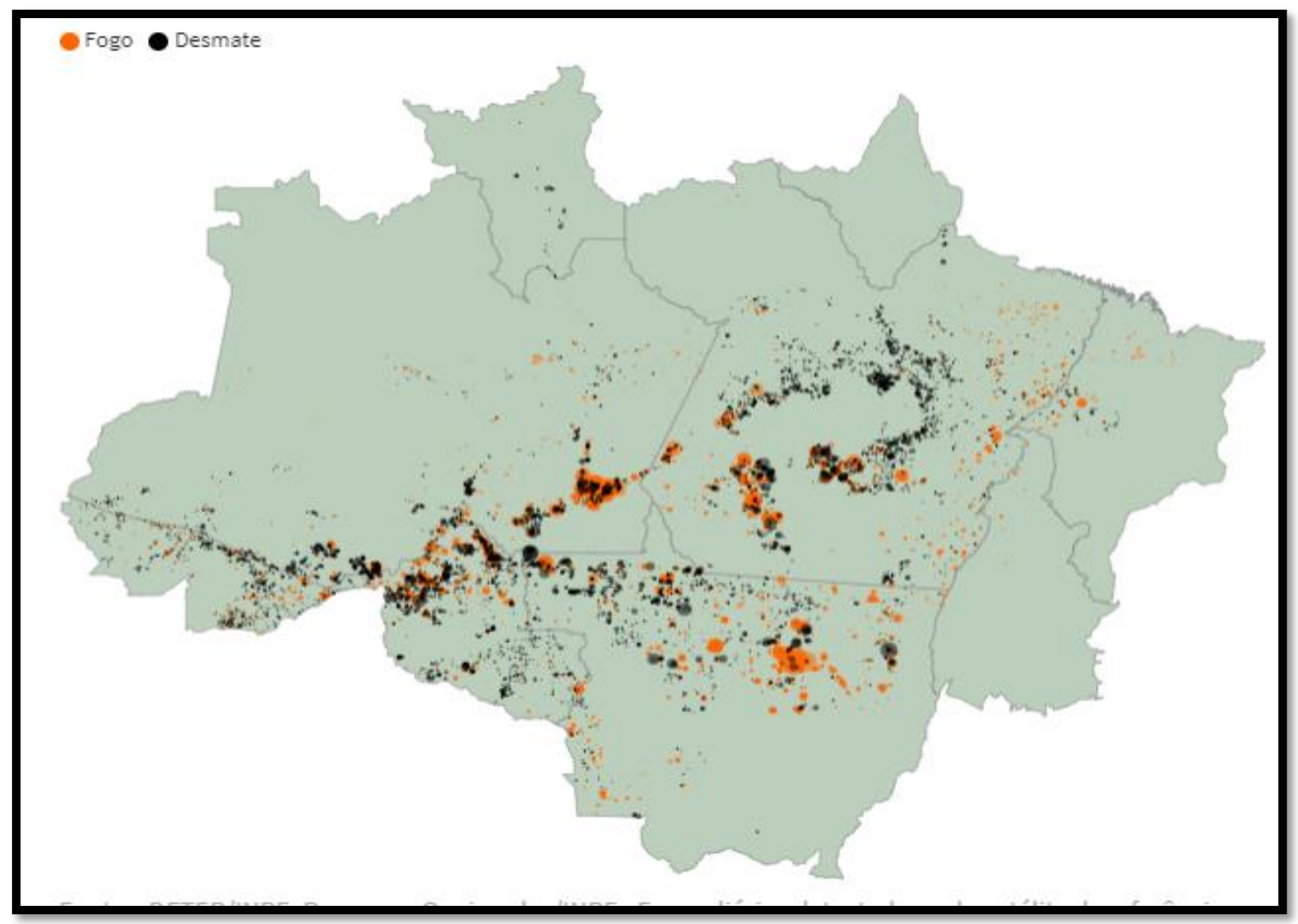

Figura 5 - Focos de Incêndio e Desmatamento.

Fonte: DETER/INPE (2019).

Tendo isso em vista, outro fato relevante perante o estudo em questão chamou atenção de pesquisadores, ONGs, governos e chefes de Estados Internacionais, que ocorreu no dia 21 de agosto de 2019, no estado de São Paulo, mais precisamente na cidade de São Paulo/SP. Por volta das 15h00min do horário de Brasília, "O dia virou noite”, o céu se escureceu, causando em seguida uma chuva intensa e escura. Contudo, o que mais chamou a atenção foi a análise realizada pelo Instituto de Química da USP (Universidade de São Paulo), com a supervisão da Doutora Pérola de Castro Vasconcelos em conjunto com o diretor do Instituto de Biociência, na qual os mesmos como uma hipótese encontraram, nas partículas das amostras da chuva, fuligens de queimadas provenientes da Floresta Amazônica (Figura 6). 


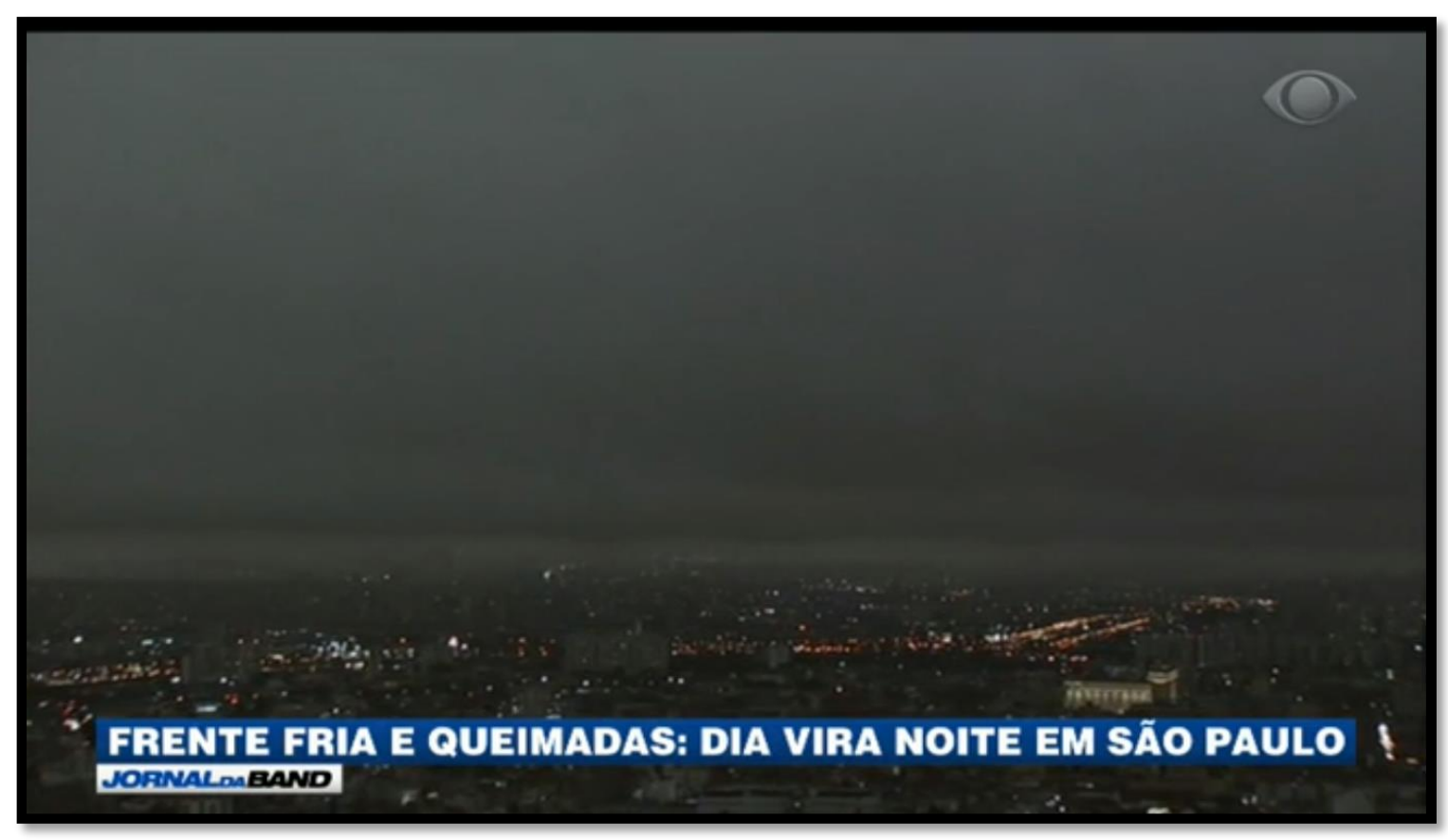

Figura 6 - Fenômeno no estado de São Paulo - São Paulo/SP.

Fonte: Band TV (21 ago. 2019).

Esses fatores, atrelados à Corrente da Amazônia e aos efeitos estufa, podem estar contribuindo para o crescimento da precipitação na bacia do PCJ ao passar dos anos, conforme mostra o Gráfico 7, onde é notório o seu aumento.

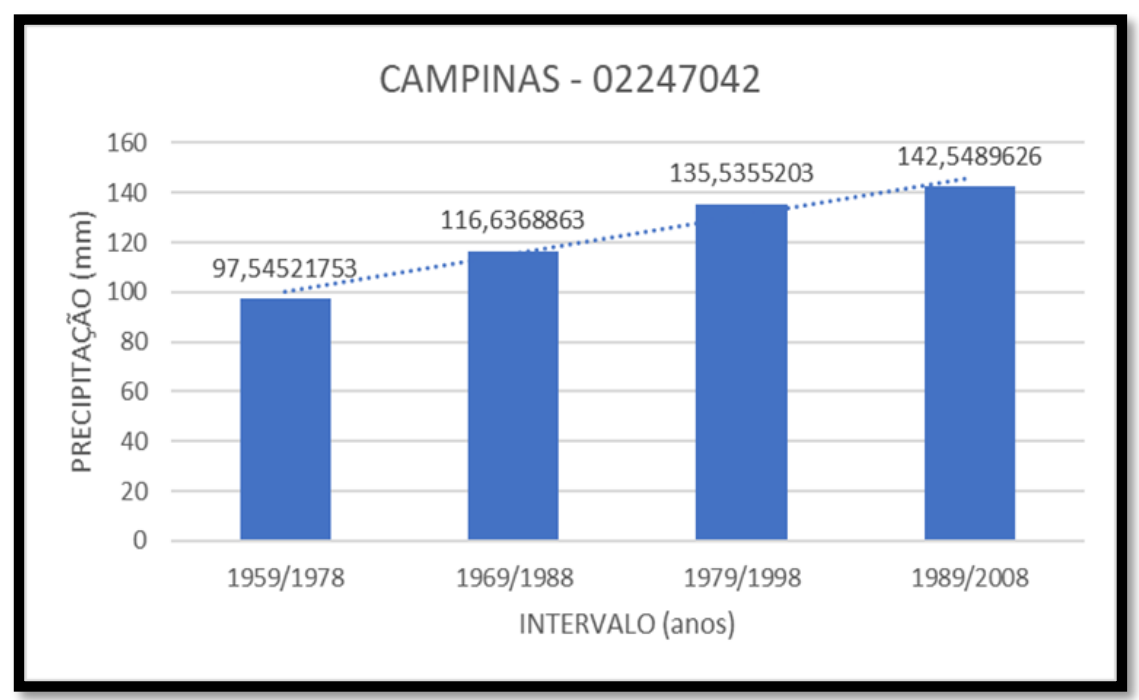

Gráfico 7 - Aumento da Precipitação na Estação 02247042 - Campinas/SP Fonte: Os autores 


\section{Considerações Finais}

Este trabalho apresenta dados importantes para o cotidiano da sociedade, cidade e Estados, quanto ao aumento da precipitação, pois com os dados obtidos, tende a serem introduzidas novas metodologias e estudos para antever possíveis problemas e consequências, dimensionamento de estruturas hídricas, como: barragens, PCHs (Pequenas Centrais Hidrelétricas), hidrelétricas, estruturas de contenção, canalizações, obras de travessias, drenagem urbana e outras obras, obtendo, assim, novos parâmetros para antever fatores de intensidade pluviométrica alterada devido ao aumento da precipitação.

As obras existentes dimensionadas com uma intensidade inferior poderão estar sujeitas a não suportar o proposto em seu projeto inicial, onde a chuva de projeto poderá ser superada em um período menor. Essas obras mencionadas poderão aplicar manutenções e outras soluções para que isso seja evitado. Isso também tem consequências na vida das pessoas que vivem próximo de córregos, encostas e outros, onde estão sujeitas a desastres e ausência de recursos. Sendo assim, os gráficos apresentados no desenvolvimento demostram que o aumento da precipitação é um fato real e sua relação pode estar ligada a uma soma de fatores, tais como o aquecimento global, processo de industrialização, incidência de raios solares no planeta, entre outros.

Em termos acadêmicos essa pesquisa pode ser continuada de fato atrelando os efeitos das queimadas e o aquecimento global ao aumento da precipitação $(\mathrm{mm})$, tendo em vista o fenômeno demonstrado na Figura 6 da cidade de São Paulo/SP, que teve seu dia totalmente escurecido no período da tarde, onde luzes automáticas de postes da cidade foram acesas e aeroportos ficaram em estado de atenção.

\section{Referências}

ABC. Amazon forest maintenance as a source of environmental services. Anais da Academia Brasileira de Ciências, Rio de Janeirno, v.80, n.1, p. 101-114, mar. 2008.

AGÊNCIA DAS BACIAS PCJ. Criada e instalada segundo as Leis Estaduais (SP) n n $^{\circ}$ 7.663/91 e ${ }^{\circ}$ 10.020/98. Entidade delegatária das funções de Agência de Água, Contrato de Gestão 003/ANA/2011. Disponível em: http://www.agencia.baciaspcj.org.br/novo/informacoes-dasbacias. Acesso em: 25 abr. 2019.

AGÊNCIA NACIONAL DE ÁGUAS (ANA). Disponível em: www3.ana.gov.br/portal/ANA/panorama-das-aguas/divisoes-hidrograficas. Acesso em: 25 abr. 2019. 
CAMILLONI, I.; BIDEGAIN, M. Escenarios climáticos para el siglo XXII. In: BARROS, V.; MENÉNDEZ, A.; NAGY, G. (ed.) El cambio climático en el rio de la Plata. Buenos Aires: CIMA/CONICET/UBA, 2005. p. 33-39.

CÂNDIDO, L. A.; SANTOS, R. M. N.; PAULIQUEVIS, T. Balanço de umidade na Amazônia e sua sensibilidade às mudanças na cobertura vegetal. Ciência e Cultura, São Paulo, v.59, n.3, p.39-43, jul./set. 2007.

CBH-PCJ - COMITÊ DAS BACIAS HIDROGRÁFICAS DOS RIOS PIRACICAB A, CAPIVARI E JUNDIAÍ. Plano de Bacia Hidrográfica 2000-2003 (Relatório Técnico Final). São Paulo: Fehidro - Fundo Estadual de Recursos Hídricos, 2004.

CNRH. Resolução n. 32, de 15 de outubro de 2003. Anexo I. Conselho Nacional de Recursos Hídricos. Brasília, DF: Ministério do Meio Ambiente, 2003.

CORREIA, F. W. S.; MANZI, A. O.; ALVALÁ, R. C. S. Modeling the impacts of land cover change in Amazonia: a regional climate model (RCM) simulation study. Theoretical and Applied Climatology, v.93, p.225-244, 2008.

CROCKFORD, R.H.; RICHARDSON, D.P. Partitioning of rainfall into throughfall, stemflow and interception: effect of forest type, ground cover and climate. Hydrological Process, West Sussex, v.14, p.2903-2920, 2000.

DAEE/SP. Disponível em: http://www.daee.sp.gov.br. Acesso em: 01 de nov. 2019.

DETER/INPI. Disponível em: http://www.observatoriodoclima.eco.br/entenda-queimadas-daamazonia-em-seis-graficos/. Acesso em: 21 ago. 2019.

FEARNSIDE, PHILIP M. Desenvolvimento da floresta amazônica: problemas prioritários para a formulação de diretrizes. Acta Amaz., Manaus, v.9, n.4, suppl.1, p.123-129,1980.

GRAMKOW, Camila L.; PRADO, Paulo Gustavo. Política Ambiental Economia verde: desafios e oportunidades. Política Ambiental/Conservação Internacional, Belo Horizonte, n. 8, jun. 2011.

HANSEN, J., SATO, M., RUEDY, R., LO, K., LEA, D.W. \& MEDINA-ELIZADE, M. Global temperature change. Proceedings of the National Academy Sciences of the USA 103: 14288-14293. 2006.

IBGE - Instituto Brasileiro de Geografia e Estatística, 2004.

IBICT. Valoração do estoque de serviços ambientais como estratégia de desenvolvimento no Estado do Amazonas. Inclusão Social, Brasília, v. 12, n.1, p. 141-151, jul./dez.2008.

INPE (Instituto Nacional de Pesquisas Espaciais). SGI 2.5 - Introdução ao Sistema de Informações Geográficas - SGI. Imagem Geosistemas, São José dos Campos: Instituto Nacional de Pesquisas Espaciais, 1995. 
IRRIGART. Engenharia e Consultoria em Recursos Hídricos e Meio Ambiente Ltda. Plano de Bacia da Unidade de Gerenciamento de Recursos Hídricos do Rio São José dos Dourados - UGRHI 18. Relatório nº83/15,v.1, 2013.

JUNK, W.J.; SHUBART, H.O.R.; OLIVEIRA, A.E. Amazônia: Desenvolvimento, Integração e Ecologia. São Paulo: Brasiliense,1983.

LINO, Geraldo Luís. A fraude do aquecimento global: como um fenômeno natural foi convertido numa falsa emergência mundial. Rio de Janeiro. Capax Dei, 2009.

MARENGO, J. A. Mudanças climáticas globais e regionais: avaliação do clima atual do Brasil e projeções de cenários climáticos do futuro. Revista Brasileira de Meteorologia, v.16, p. 1-18. 2001.

MENDONÇA. F. (Org.) Clima Urbano. São Paulo: Editora Contexto, 2003.

MMA. Mudanças climáticas globais e seus efeitos sobre a biodiversidade: caracterização do clima atual e definição das alterações climáticas para o território brasileiro ao longo do século XXI. Brasília: MMA, Ministério do Meio Ambiente. 2007.

MMA. GEO Brasil: Recursos Hídricos. Brasília: Ministério do Meio Ambiente; Agência Nacional de Águas; Programa das Nações Unidas para o Meio Ambiente, 2007.

NOBRE, C. A.; ASSAD, E. D.; OYAMA, M. D. Mudança ambiental no Brasil: o impacto do aquecimento global nos ecossistemas da Amazônia e na agricultura. Scientific American Brasil, São Paulo, n. 12, p. 70-75, 2005. (Especial Aquecimento).

PAPINI, S. Vigilância em saúde ambiental. Uma nova área da Ecologia. Editora Atheneu, 2009.

RIGHETTO, A. M. Hidrologia e recursos hídricos. São Carlos: EESC/USP, 1998.

SALATI, Enea. O clima atual depende da floresta. In: Salati, E.; Junk, W.J.; Schubart, H.O.R; Oliveira, A. (eds). Amazônia, desenvolvimento, integração e ecologia. São Paulo, Brasiliense, 1983, p. 15-44. 